\title{
ADAPTING SCIENCE CLASSROOMS FOR VISUALLY IMPAIRED STUDENTS: ISSUES, CHALLENGES AND PLAUSIBLE SOLUTIONS
}

\author{
Shruti Pandey ${ }^{1 i}$, \\ Yogendra Pandey ${ }^{2}$ \\ ${ }^{1}$ Assistant Professor, \\ Faculty of Education, \\ Banaras Hindu University, \\ India \\ ${ }^{2}$ Associate Professor, \\ Faculty of Education, \\ Banaras Hindu University, \\ India
}

\begin{abstract}
:
The goals of education for the students with special needs are no different than the educational goals for sighted children. However, the means of attaining these goals are more complex and demand significant modifications, adaptations and extensions of the curriculum and the teaching process. Research shows that students with exceptionalities such as visual impairment are better academically engaged in daily classes and have opportunities for active learning. Consequently, it is important to develop systematic methods for teaching concepts. The instructor of students with visual impairment will logically find the principles that direct the learning process. Concepts for students use difficult methods and oral examples should be carefully taught where appropriate. The design of individual courses differs from the student's needs and from the various circumstances under which a concept is to be enrolled. In broader concept science as a subject is dedicated to developing scientific attitudes such as objective outlook, spirit of enquiry, truthfulness and integrity, inventiveness, accuracy and precision. Therefore, in the science classrooms science educators must respond to their needs by motivating science and laboratory and science students with visually impaired conditions. Inadequate funding is the biggest problem in giving students with visual impairment fair access to education. The amount of teacher assistance or integration assistance is inadequate to meet the requirements. We do not have enough preparation and professional support in relation to the practical aspects of the science curriculum. This paper provides a theoretical perspective for the students with visual impairment to understand the challenges of entering science classrooms. The ideas in this article will help educators create opportunities for visually impaired students to improve science learning.
\end{abstract}

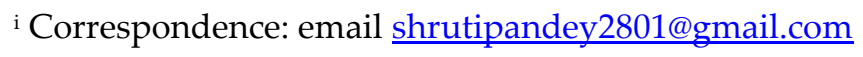


Keywords: visually impaired students, adaptations, science classrooms, accessible \& assistive technologies

\section{Understanding Visual Impairment}

Vision is the primary means of understanding of our world (Advani, 1992). There are believed to be 19 million blind students around the world (WHO, 2012). The students with visual impairment experience many problems, like behaviour problems, as the concepts of congenital blindness are limited, since they have not all the necessary sensations. Concept development relies on sensory stimulation of different senses; and students who are visually impaired may find it hard to perceive such stimuli in other senses. It also would be difficult for them to view objects in space or the dimension or to establish abstract concepts. The students with visual impairment have many issues, such as behaviour problems, because the understanding of congenital blindness is limited because they lack all the requisite feelings. Concept development relies on the sensory stimulation by different senses, and it would be impossible for students with vision impaired to perceive such things by other senses. It would also be hard to understand objects in space or dimension or to create abstract concepts (Heyl and Hintermair, 2015).

The educational aims of the blind are no different from those of the student with vision. Nevertheless, the means to accomplish these objectives are more complex and require substantial changes, revisions and extensions to the curriculum and to the teaching process. When the blind child entered school, the experience was often restricted and the resultant language deficiencies were also limited, and concepts were not well formed due to a limited opportunity for first-hand experience and observation. Poor balance, poor orientation and mobility skills, and lack of preparation, and many life competencies, including self-care, are the reasons for a lack of ability for blind students to learn from secondary schooling. Treatment can either be absent or underdeveloped in care of possessions and playing skills. In comparison to a sighted child, the vocabulary of the blind child often is limited by the lack of visual experience; visual thinking styles, visual- motor skills and certain basic world concepts are lacking because visual perception is absent. The regular school program presumes the basic skills and gives students a curriculum that teaches them how to read, write, arithmetically and gather information in different areas of the subject and develop new skills using these skills (Farrel, 2006).

Special education for specific visual needs was created by students to address their specific needs and the laggard for development in the social and emotional climate of many blind students. Social interaction is based upon communication both verbally and visually. Nevertheless, the blind child has no clear hints. They cannot see how others express their feelings. Because many blind students spending most of their time with adults, their social skills are often not adequate to communicate with their peers effectively. They might also have no positive self-image to form the foundation for potential social and emotional development. It can then be seen that a blind student needs 
an extended program, the expertise of a qualified prof. Nevertheless, studying in the classroom should not be all a blind child gets from the experience of the school. The acquisition of these skills through opportunity is the subject of peer engagement, acceptance and appraisal and reflects individual interests. To addition to their blindness, a great majority of blind students have significant physiological and/or psychological disorders. Comprehensive plans must be developed to address psychological and social growth and the basic curriculum to effectively meet the multi-special needs of blind students.

\section{Visually Impaired Students and Science}

Science experiences often rely on visual data, and we don't know how difficult it is for a visually impaired student to be in a scientific laboratory. Chemical experiments cause problems, as they require visual observations in most cases, such as chemical reactions. If bubbles occur during a chemical reaction, or when a chemical reaction involves a temperature change, the blind student may feel the reaction occurring by listening or touching. However, if a colour change is called for in the reaction, the blind student must make his / her sighted partner clear the reaction to the students. Students without a clear vision also lack such basic concepts (e.g. left / right, up / down, over-down) and can fight for the convergence of the essential components of their world. Such values should be learned for visually impaired students in order to expand their knowledge base and to communicate with sightseeing students whenever possible. It is therefore important to develop systematic methods for teaching concepts. The student teacher with a visual impairment should find rational ways of thinking about subjects that direct the teaching process. When needed, students with convincing instruments as well as verbal examples should be carefully taught concepts. Flexibility is critical since the design of individual courses depends on the needs of the students and on the circumstances under which a concept should be taught

Special needs teachers should also be versatile when determining the understanding of concepts by a pupil visually. When assessing specific concepts, all verbal and output responses should be elicited from the student. It helps clarify the relationship between the performance of a stud gage and the ability to perform. Considering the visual functioning of the pupil, the instructor must use his or her discretion to assess which intellectual levels a student can be expected to achieve. Eichenberger (1974) argued that since a blind person is completely incapable of notes and documents, working with a creative pair to conduct experiments involving data is useful to a blind student. The pair will explain the result and record details for the blind student while the blind student operates the equipment. Blind students demonstrated that they could do various computational tasks such as graphics, angle estimation, rock and mineral classification and mathematical solutions. 


\section{Strategies of Coping Issues Related to Science}

Several strategies may be adapted in order to cater the specific needs of visually impaired students as follows:

a. Classroom Accommodations: When allowing visually impaired students, the physical arrangement of the classroom must also be considered. In case of a change in the space layout or of a temporary obstacle in the room, such as a display or video screen, unwanted obstacles in the room are to be removed and students with disabilities should be notified (Lewis and Doorlag, 2003).

Thompson (2003) argued about dividing the classroom into different learning stations. She says there may be a barrel of sand, a furnace or suede board and balls for relaxation in a touch-kinaesthetic station. There may also be an environment in which highly active students can move or step forward. Auditing students may benefit from a station where authors' recordings read their work or music for learners to hear while reading or writing. Students who consider it helpful to sub-vocalize may have access to cups to talk to so they can read passages without disrupting other students. Ideally a visual station will allow students to play or read content. Watching yourself complete a job effectively will serve as a great boost to morale. Thompson also suggests that candles, perfume streaks and potpourri be included in training stations as scents can stimulate memories, help connect learning with real life experiences and help to remember new concepts.

b. Adapting Experiments: Distinguishing the student's work area with a spill tray help them to trust their environment. It allows the student to differentiate between the work area and a waste plate to trust their environment. Tactile signage such as bumpon beaker and other equipment can enable students to operate correctly with tact equipment such as rulers, tape metering devices, and speech clocks, thermometers, balance sheets and calculators. Talks may change the sound / scent / perceived and visible results. For electric experiments, buzzers can be used instead of bulbs. With the assistance of a hearing light sensor, an audible sound can be produced for the radiation optical experiment, according to the reflected light intensity (Baughman and Zollman, 1977).

c. Adaptations in Diagrams and Graphs: If a diagram is used for example only, it applies to an explanatory text that could be easier to understand for the visually impaired student. If an object is shown by a diagram, use it if possible. If possible. It will allow the teachers to better show the material if the diagrams concentrate on the core concept and remove irrelevant information. (Ricker and Rodgers, 1981).

d. Exploration: Allow students to use bidirectional exploration to get a sense of the scale and the interaction between sections of the object. Using professional materials such as clay modelling may help to create simple models that reflect what visual students can see-like cells under a microscope. Considering whether a model represents the real object's texture and can aid definition can enhance the process of learning. One 
should consider that how we can use visual language in the entire class when vision is needed.

e. Peer Support: The inclusion of non-visually impaired students in the science laboratory should also be planned. It is recommended that when students are going to school, the rule that visually impaired students always have the right of way and that students keep the islands as barrier-free as possible. Students should be warned of moving chairs, other classroom furnishings and materials without first warning students with visual impairments. Students who are not visually impaired should be aware of the position of guides and warned that they are not regarded as animals. The teacher will ask volunteers to join the class.

f. Preventive Measures: Like all students, students with impaired vision should wear rubber gloves, apron, and glasses during a lab lesson, especially when working with chemicals (Kucera, 1993). When needed, glassware and rubber mat should be replaced with plastic measuring devices and containers, especially for transferring liquids, to stabilize the glassware. Where appropriate, hotplates should also be recommended as a substitute for burners.

g. Lab Equipment Accommodations: To visually impaired students, growing attention is paid to the production and alteration of laboratory materials. For those students who read using the Braille system, braille label makers are available. In the research classroom, science teachers can use these label makers in a variety of ways. For example, labelling can be applied to containers, glassware and other laboratory equipment, including chemical and reagent. For students with normal vision and with a Braille label for the visually impaired, each piece of equipment may be put on a lab table together with a numbered index card with the name of the object in the printed form. The instructor can then explain each item's purpose as it is handed over to the student with visual impairment. (Kumar, Ramasamy \& Stefanich, 2001)

h. Modifying Demonstrations: Demonstrations are part of science; however, students with visually impaired disabilities often must be changed. The teacher will rely more on verbal descriptions of scientific processes rather than on written representations of the example to enable student with visual impairments to construct a cognitive image of what happens. The demonstrations along with visual explanation of the experiment can help students develop the ability to adequately track and communicate effectively if they have already accurately described creative students. (Ratliff, 1997).

i. Practical Assessment: Many students with visual impairment requires changes in the evaluation procedures. Teachers should use a realistic assessment rather than a formal assessment as far as possible. In a three-dimensional model, for example, a visually impaired student will feel and verbally understand the complex organelles while evaluating any cell structure. The text assessments for people who read with braille are to be translated in braille, if they have not read. Braille note-takers can be used instead which will help to answer questions by typing the answers. 


\section{Conclusion \& Suggestions for Further Research}

Science for the visually impaired is a challenging subject for which to prepare and instruct, as well as to take as a student unless the right accommodations, modifications and assistive technology are used. With the right methods and assistive technology, the science student who is visually impaired, can learn and do the same assignments as other science students. Instructing students using assistive technology, accommodations, modifications and specialized training is often very expensive. Teacher preparation programs for blind and visually impaired instruction are not plentiful and inconsistent in terms of proficiency levels acquired in assistive technology and methods upon completion (Ambrose, Zaken \& Bozeman, 2010; Wild \& Allen, 2009). As there are plenty of issues in the teaching and learning of science but several adaptations in this field will to accommodate visually impaired students in a better way for better future.

\section{Conflict of Interest Statement}

The authors declare no conflicts of interests.

\section{About the Authors}

Shruti Pandey is an Assistant Professor in Special Education at Faculty of Education, Banaras Hindu University, India with a teaching experience of 7 years. Her area of interest is visual impairment, inclusive education and pedagogy of teaching science.

Yogendra Pandey is an Associate Professor in Special Education at Faculty of Education, Banaras Hindu University, India with a teaching and research experience of over 15 years with interest in inclusive education.

\section{References}

1. Advani, L. (1992). Effects of visual disability on cognitive development. In Verma, A.K. (Ed.), Handbook for the teachers of the visually handicapped. Dehradun, India: Rohini.

2. Ambrose-Zaken, G., \& Bozeman, L. (2010). Profile of personnel preparation programs in visual impairment and their faculty. Journal of Visual Impairment $\&$ Blindness, 104(3), 148-169.

3. Baughman, J. \& Zollman, D. (1977). Physics labs for the blind. Physics Teacher, 15(6), 339-342.

4. Eichenberger, R. J. (1974). Teaching science to the blind. Student Science Teacher, 41(9), 53-54.

5. Farrell, M. (2006). The Effective Teachers' Guide to Sensory Impairment and Physical Disability Practical Strategies. Now York: Routledge.

6. Heyl, V. \& Hintermair, M. (2015). Executive Function and Behavioral Problems in Students with Visual Impairments at Mainstream and Special Schools. Journal of Visual 
Impairment \& Blindness retrieved from https://pdfs.semanticscholar.org/7879/ on $11 / 11 / 2019$

7. Kucera, T. J., ed. 1993. Teaching Chemistry to Students with Disabilities. Washington, D.C.: American Chemical Society.

8. Kumar, D., Ramasamy, R. \& Stefanich, G. (2001). Science for students with visual impairments: Teaching suggestions and policy implications for secondary educators. Electronic Journal of Science Education, 5(3). Retrieved June 5, 2003, from http://unr.edu/homepage/crowther/ejse/kumar2etal.html.

9. Lewis, R. B., and D. H. Doorlag (2003). Teaching Special Students in General Education Classrooms. 6th ed. Old Tappan, N.J.: Merrill

10. Ratliff, J. L. (1997). Chemistry for the visually impaired. Journal of Chemical Education 74,710-711.

11. Ricker, K. S., \& Rodgers, N. C. (1981). Modifying instructional materials for use with visually impaired students. The American Biology Teachers. 43(9), 490-501.

12. Thompson, S. M. (2003). Multisensory learning in inclusive classrooms. Academic Exchange Quarterly. retrieved on 03/12/2019 from https://www.thefreelibrary.com/Multisensory+learning+in+inclusive+classrooms.a0111848857\#: :text=Multisensory\%20teaching\%2C\%20a\%20type\%20of,into\%20the \%20general\%20education\%20classroom.\&text=Students $\% 20$ with $\% 20$ disabilities $\% 20$ are $\% 20$ moving $\% 20$ into $\% 20$ general $\% 20$ education $\% 20$ classrooms $\% 20 \mathrm{in} \% 20$ record $\% 2$ 0numbers.

13. Wild, T., \& Allen, A. (2009). Policy analysis of science-based best practices for students with visual impairments. Journal of Visual Impairment \& Blindness, 103(2), 113-117.

14. WHO (2012). Global Data on Visual Impairments 2010. retrieved on 17/11/2019 from https://www.who.int/blindness/globaldatafinalforweb.pdf. 
Authors will retain the copyright of their published articles agreeing that a Creative Commons Attribution 4.0 International License (CC BY 4.0) terms will be applied to their work. Under the terms of this license, no permission is required from the author(s) or publisher for members of the community to copy, distribute, transmit or adapt the article content, providing a proper, prominent and unambiguous attribution to the authors in a manner that makes clear that the materials are being reused under permission of a Creative Commons License. Views, opinions and conclusions expressed in this research article are views, opinions and conclusions of the author(s). Open Access Publishing Group and European Journal of Special Education Research shall not be responsible or answerable for any loss, damage or liability caused in relation to/arising out of conflict of interests, copyright violations and inappropriate or inaccurate use of any kind content related or integrated on the research work. All the published works are meeting the Open Access Publishing requirements and can be freely accessed, shared, modified, distributed and used in educational, commercial and non-commercial purposes under a Creative Commons Attribution 4.0 International License (CC BY 4.0). 